\title{
The impact of multisite pain on functional outcomes in older adults: biopsychosocial considerations
}

This article was published in the following Dove Medical Press journal: Journal of Pain Research

\author{
Katie A Butera' \\ Shannon R Roff ${ }^{2}$ \\ Thomas W Buford ${ }^{3}$ \\ Yenisel Cruz-Almeida ${ }^{4}$ \\ 'Department of Physical Therapy, \\ College of Public Health and Health \\ Professions, University of Florida, \\ Gainesville, FL 32610, USA; ${ }^{2}$ Charles \\ River Laboratories Inc., Frederick, MD \\ 2I70I, USA; ${ }^{3}$ Department of Medicine, \\ School of Medicine, University of \\ Alabama at Birmingham, Birmingham, \\ AL 35294, USA; ${ }^{4}$ Department of Aging \\ \& Geriatric Research, Institute on \\ Aging, Pain Research \& Intervention \\ Center of Excellence, Center for \\ Cognitive Aging \& Memory, University \\ of Florida, Gainesville, FL 32610, USA
}

Correspondence: Yenisel Cruz-Almeida Institute on Aging, Pain Research and Intervention Center of Excellence, Cognitive Aging and Memory Translational Program, University of Florida, PO Box II26/0, Gainesville, FL 32610, USA

Tel +I 3522945845

Fax +I 3522735920

Email cryeni@ufl.edu

\begin{abstract}
Multisite pain, or pain that occurs simultaneously at $>1$ anatomical site, is more prevalent than single-site pain. While multisite pain affects over half of older adults, it remains an understudied pain entity that may have important functional implications in an aging population. Greater understanding of this complex pain entity from a biopsychosocial perspective is critical for optimizing clinical and functional outcomes in older adults with pain. Therefore, the primary purpose of this review is to summarize the relationship between multisite pain and functional outcomes in older adults to further elucidate the impact of multisite pain as a distinct entity within this population. A comprehensive literature search revealed 17 peer-reviewed articles. Multisite pain in older individuals is associated with reductions in several physical function domains: 1) lower-extremity mobility; 2) upper-extremity impairments; 3) balance and increased fall risk; and 4) general disability and poor physical function. Further, multisite pain in older individuals is associated with psychological dysfunction (eg, anxiety and depressive symptoms) and social factors (eg, income and education). Overall, this review highlights the scant literature investigating the functional implications of multisite pain in an aging population. Further, while multisite pain appears to have functional consequences, the neurobiological mechanisms contributing to this relationship are unknown. Thus, how this pain characteristic may contribute to the variability in pain-related functional outcomes among older adults is not clear. Future investigations are strongly warranted to advance the understanding of multisite pain and its broad impact on physical and psychosocial function in older adults.
\end{abstract}

Keywords: multiple pain locations, multiple pain sites, social function, dysfunction, disability, physical function, social factors

\section{Introduction}

Multisite pain, or pain that occurs simultaneously at $>1$ anatomical site, is a prevalent pain condition. ${ }^{1-3}$ In the general population, those reporting single-site pain often report pain at other sites, ${ }^{1,4-8}$ additionally, single-site pain increases the risk for pain at other sites. ${ }^{9}$ The common occurrence of multisite pain is highlighted in findings from a large epidemiological sample where $16.8 \%$ of responders reported localized musculoskeletal pain compared to $53 \%$ of responders who reported pain at $>1$ site. ${ }^{8}$ Notably, evidence suggests that over half of older adults experience multisite pain. ${ }^{10-12}$ One study indicated that $\sim 74.9 \%$ of their older adult sample reported multiple pain sites. ${ }^{12}$

While multisite pain is highly prevalent in older adults, it remains an under-appreciated and understudied pain characteristic that may represent a distinct pain condition with potential functional implications in this population. Experiencing pain at multiple sites may have greater impact on physical fitness, emotions, or daily and social activities 
compared to single-site pain. Furthermore, consideration of multisite pain in an aging population is critical for these individuals as they often demonstrate greater declines in physical and psychological functions as well as significant levels of chronic pain. ${ }^{12}$ Overall, a stronger understanding of the complex biopsychosocial relationships contributing to multisite pain in older adults may provide key insight needed to optimize clinical and functional outcomes within this population (Figure 1). Therefore, the primary purpose of this literature review is to summarize the relationship between multisite pain and functional outcomes (physical function and psychosocial function) in older adults to further elucidate the relevance of identifying and studying multisite pain as a distinct disease entity using a biopsychosocial framework of pain and aging.

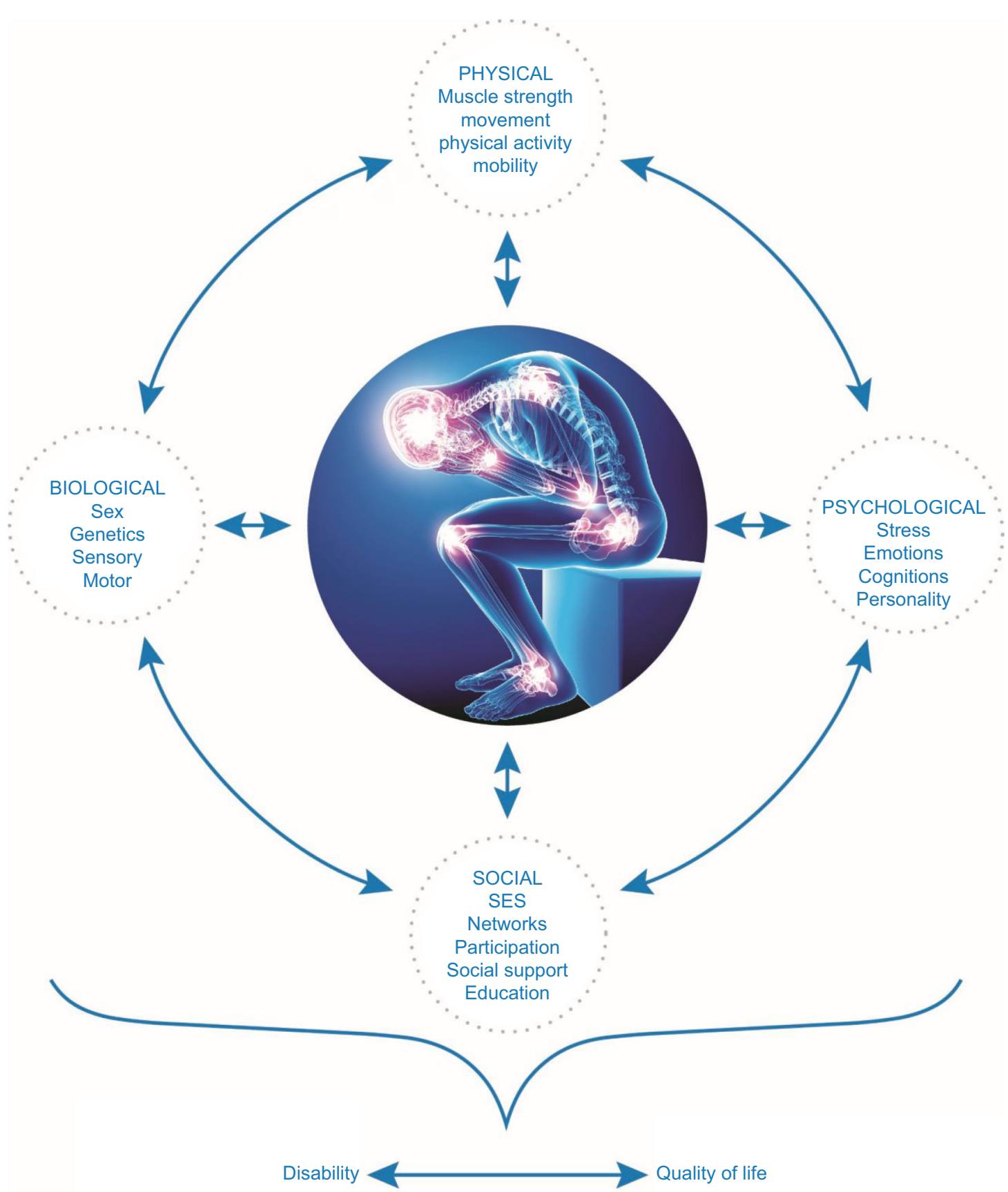

Figure I Conceptual model of the biopsychosocial considerations of multisite pain in older adults.

Note: This model represents multisite pain using a biopsychosocial framework and depicts the integration of multiple, complex relationships that comprise this distinct disease entity. 


\section{Methods}

A comprehensive search across several databases was performed to extract peer-reviewed articles published in 2018 or earlier (Figure 2). Databases included PubMed, Google Scholar, and Web of Science. Articles examining multisite pain in older adult populations were targeted through the use of key terms and their combinations; these included but were not limited to: "multisite pain", "multiple pain locations", "number of pain sites", psychosocial", "psychological function", "psychological distress", "physical function”, "physical activity", "function", "physical dysfunction", "dysfunction", "disability", "participation", "networks", and "social function". All titles returned from PubMed and Web of Science searches were examined; however, for pragmatic reasons, only the first 200 results from the Google Scholar searches were examined as searches of this database consistently returned $>1,000$ results. Potential articles for inclusion were identified based on title relevance and then based on a review of the full abstract; finally, a full-text review of remaining articles was conducted. Additionally, the reference section of a relevant extracted article was searched to identify additional potential articles for inclusion. Articles were included if they met all of the following criteria: 1) the study included a clearly defined measure of multisite pain; 2 ) the study population included only individuals of age 65 or older; 3) the study included physical, psychological, and/or social measures; and 4) the study data analyses were structured to examine the relationship between multisite pain and physical, psychological, and/or social measures. Articles were excluded if they met one or more of the following criteria: 1) the study population included individuals $<65$ years old; 2) the study did not adequately define multisite pain and/ or only examined widespread pain; 3) the study did not use appropriate analyses for the primary purpose of this review; and 4) the study did not include appropriate measures for the primary purpose of this review. Additionally, articles were excluded if they were review articles, intervention studies, or measurement studies. Figure 2 illustrates the results from the search strategy.

\section{Results}

The search yielded 17 peer-reviewed articles investigating multisite pain and its associated physical and psychosocial functional implications among older adults. Tables 1 and 2 provide a comprehensive list of included articles. Overall, multisite pain in older individuals is associated with reductions in several aspects of physical function including: 1) reduced lower-extremity mobility; 2) upper-extremity impairments; 3 ) decreased balance and increased fall risk; and 4) higher general disability and

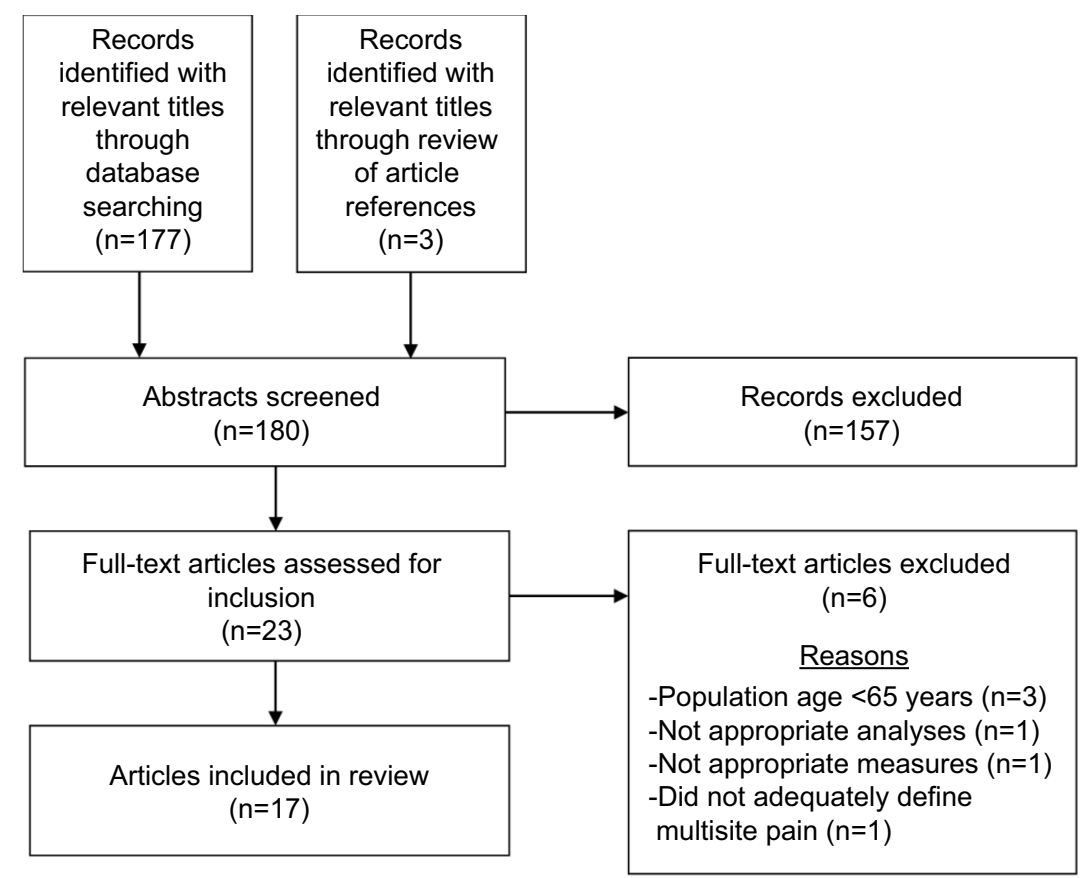

Figure 2 Search strategy flowsheet.

Note: This flowsheet illustrates the search strategy used to identify included and excluded articles for this review. 


\begin{tabular}{|c|c|c|c|c|c|c|c|}
\hline 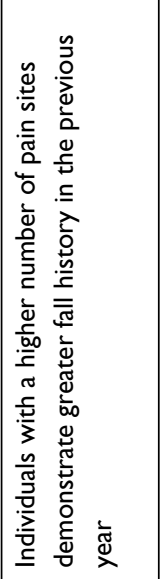 & 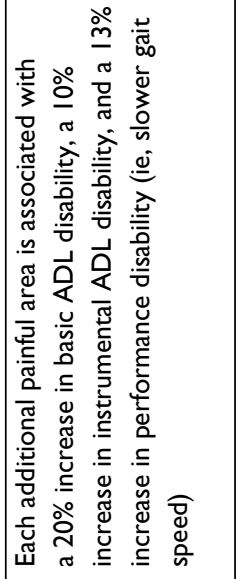 & 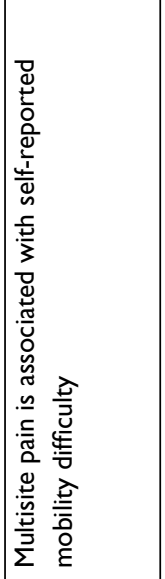 & 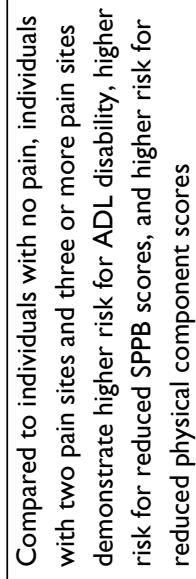 & 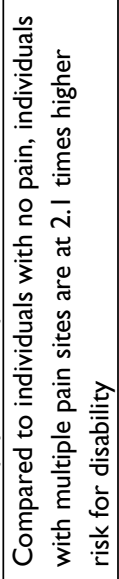 & 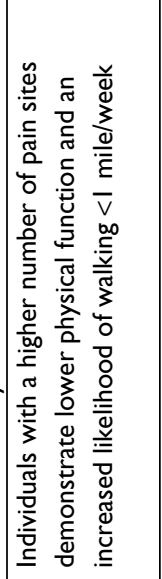 & 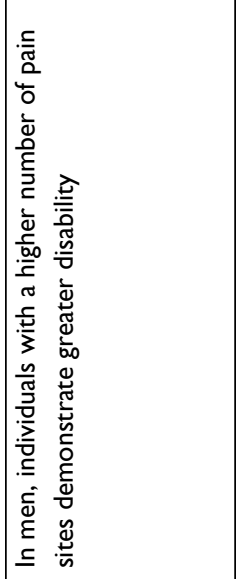 & 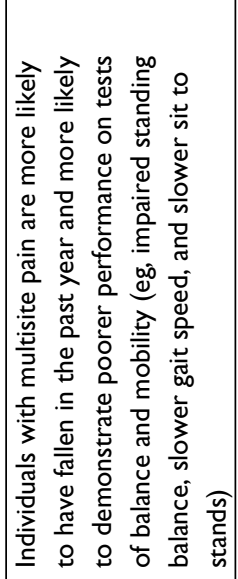 \\
\hline 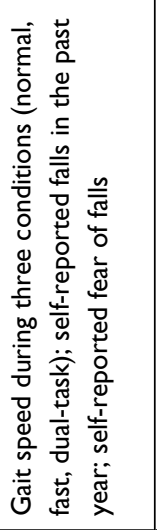 & 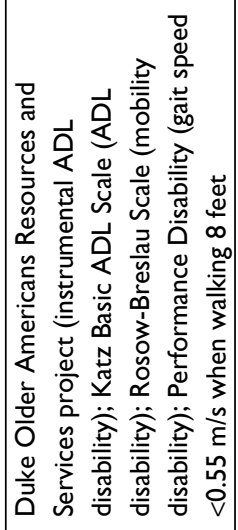 & 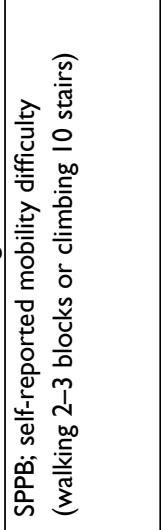 & 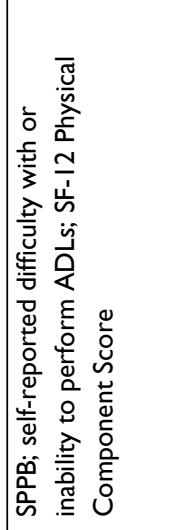 & 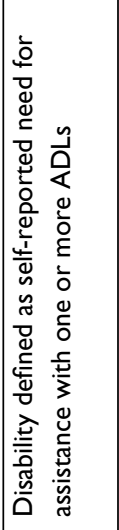 & 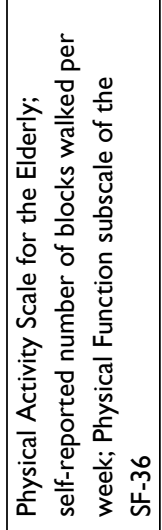 & 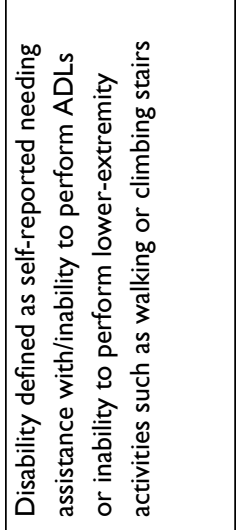 & 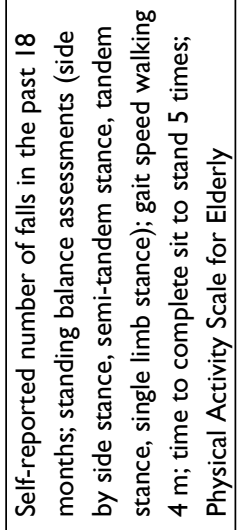 \\
\hline 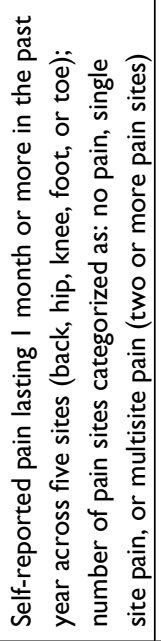 & 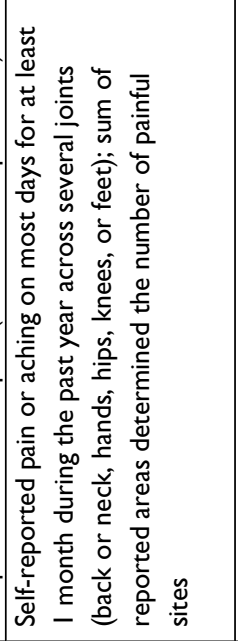 & 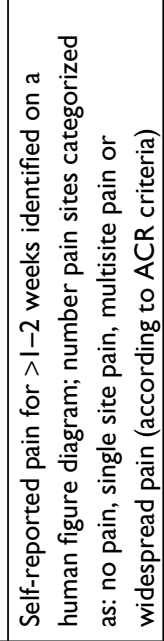 & 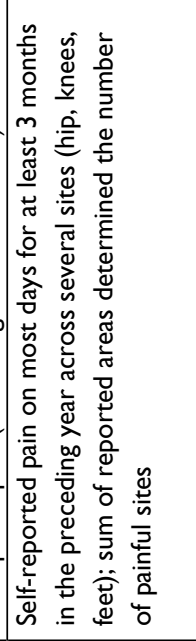 & 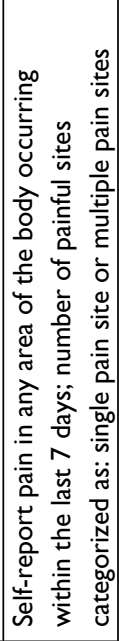 & 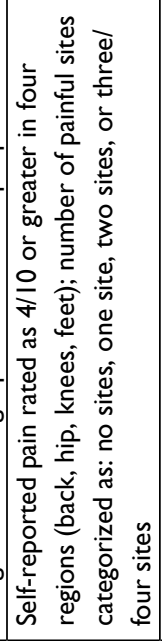 & 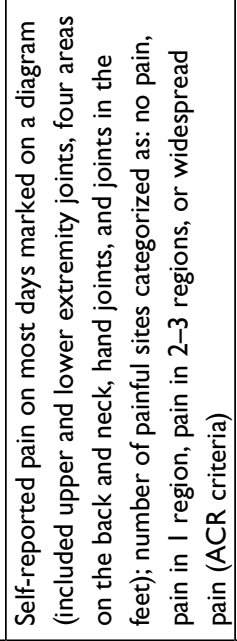 & 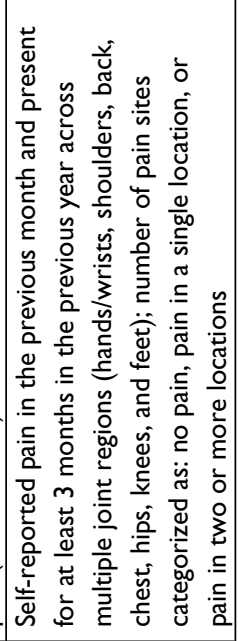 \\
\hline 㟋 & 足 & 只 & $\stackrel{R}{i}$ & 品 & R & 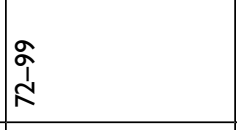 & 只 \\
\hline$\cong$ & $\begin{array}{l}\infty \\
\infty\end{array}$ & 㤐 & $\stackrel{\aleph}{\kappa}$ & ఫ્ત & $\stackrel{\tilde{m}}{\tilde{m}}$ & 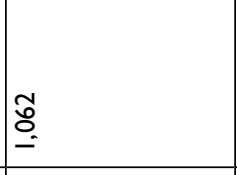 & $\frac{g}{d}$ \\
\hline 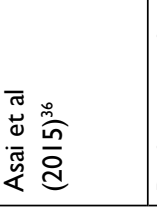 & 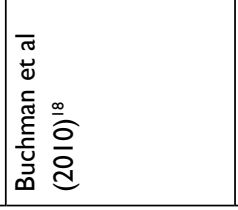 & 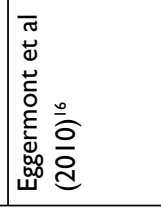 & 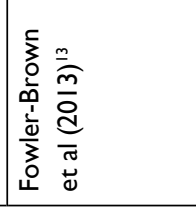 & 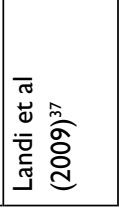 & 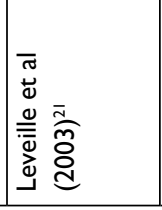 & 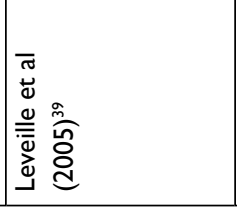 & 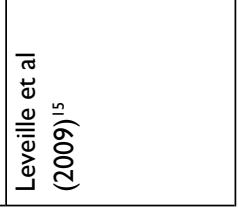 \\
\hline
\end{tabular}




\begin{tabular}{|c|c|c|c|c|c|c|}
\hline 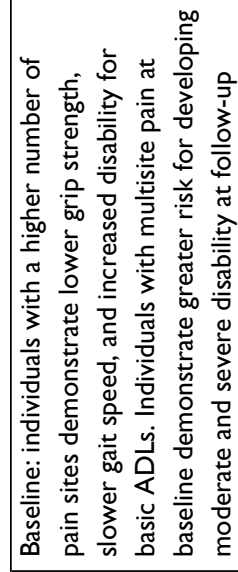 & 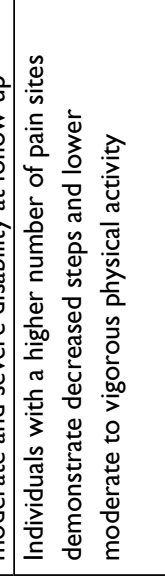 & 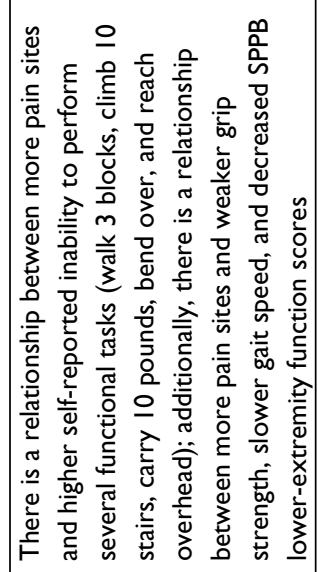 & 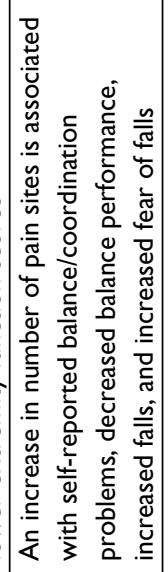 & 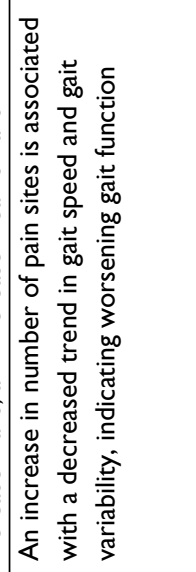 & 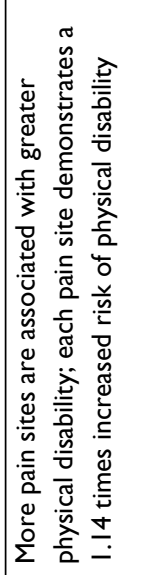 & 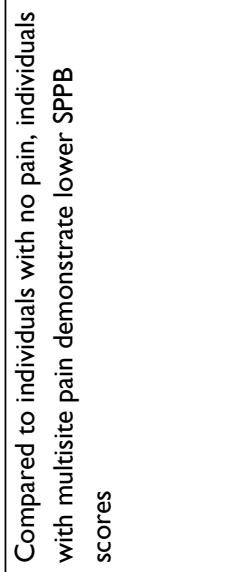 \\
\hline 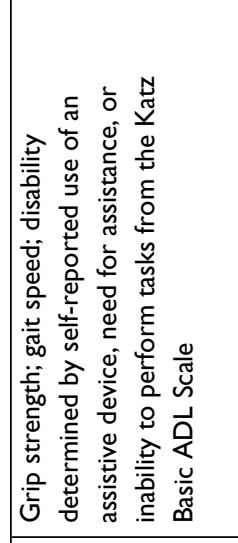 & 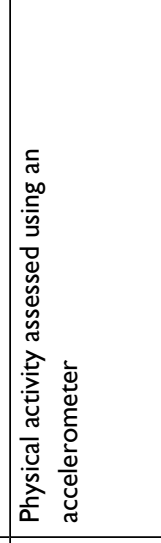 & 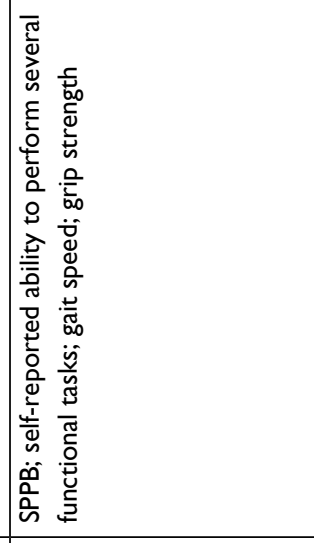 & 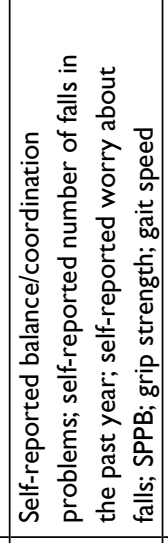 & 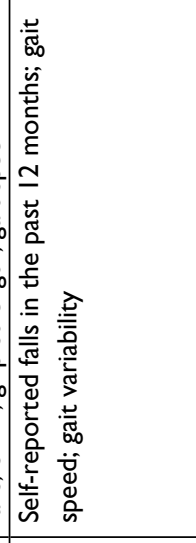 & 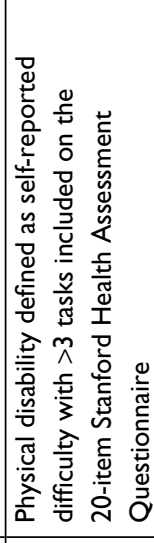 & \\
\hline 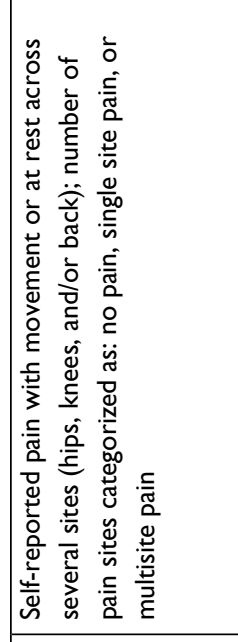 & 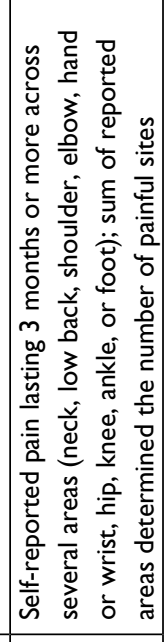 & 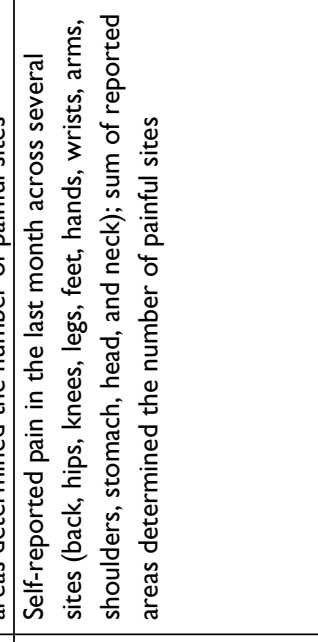 & 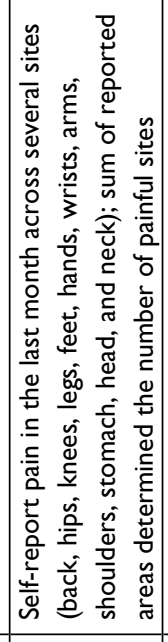 & 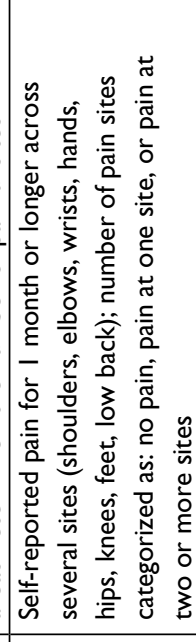 & 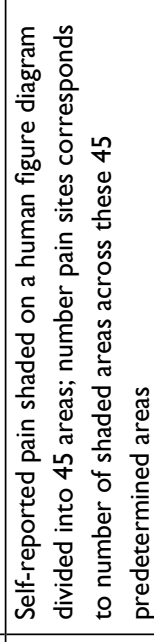 & 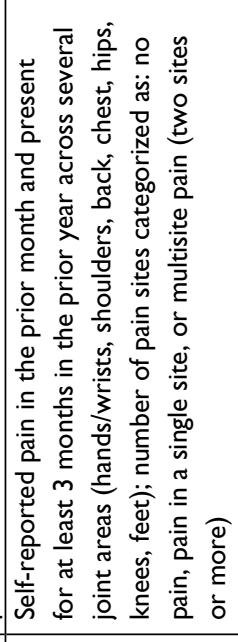 \\
\hline 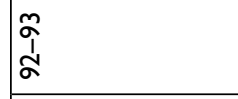 & 兗 & 兗 & 望 & 㟋 & 㞻 & $\stackrel{\circ}{\wedge}$ \\
\hline 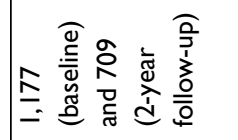 & î & 亯 & 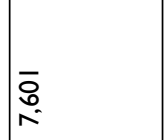 & $\stackrel{ \pm}{\sim}$ & 急 & 祢 \\
\hline 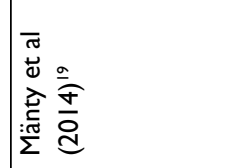 & 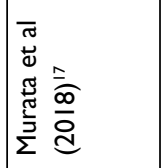 & 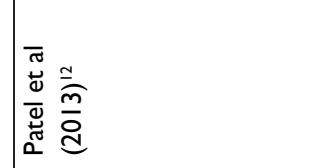 & 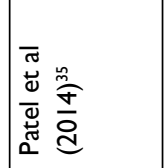 & 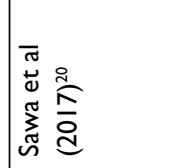 & 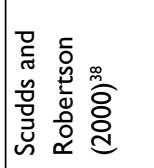 & 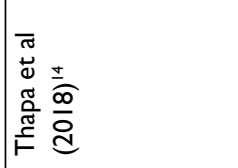 \\
\hline
\end{tabular}


Table 2 Summary of articles indicating associations between multisite pain and psychosocial function in older adults

\begin{tabular}{|c|c|c|c|c|c|}
\hline Reference & $\begin{array}{l}\text { Number of } \\
\text { subjects }\end{array}$ & $\begin{array}{l}\text { Age } \\
\text { (years) }\end{array}$ & Pain measure & $\begin{array}{l}\text { Psychological and/or } \\
\text { social measure }\end{array}$ & Result \\
\hline $\begin{array}{l}\text { Buchman } \\
\text { et al } \\
(2010)^{18}\end{array}$ & 898 & $\geq 65$ & $\begin{array}{l}\text { Self-reported pain or aching on most } \\
\text { days for at least I month during the } \\
\text { past year across several joints (back or } \\
\text { neck, hands, hips, knees, or feet); sum of } \\
\text { reported areas determined the number } \\
\text { of painful sites }\end{array}$ & $\begin{array}{l}\text { Self-reported years of } \\
\text { education }\end{array}$ & $\begin{array}{l}\text { An increase in number of pain } \\
\text { sites is associated with fewer } \\
\text { years of education }\end{array}$ \\
\hline $\begin{array}{l}\text { Denkinger } \\
\text { et al } \\
(20 \mid 4)^{40}\end{array}$ & 1,506 & $\geq 65$ & $\begin{array}{l}\text { Self-reported pain across I } 3 \text { body } \\
\text { regions; sum of reported areas } \\
\text { determined the number }\end{array}$ & $\begin{array}{l}\text { Hospital Anxiety } \\
\text { Depression Scale }\end{array}$ & $\begin{array}{l}\text { Individuals with a higher } \\
\text { number of pain sites } \\
\text { demonstrate an increased risk } \\
\text { of depression }\end{array}$ \\
\hline $\begin{array}{l}\text { Leveille } \\
\text { et al } \\
(2003)^{21}\end{array}$ & 325 & $75-85$ & $\begin{array}{l}\text { Self-reported pain rated as } 4 / 10 \text { or } \\
\text { greater in four regions (back, hip, knees, } \\
\text { feet); number of painful sites categorized } \\
\text { as: no sites, one site, two sites, or three/ } \\
\text { four sites }\end{array}$ & Self-reported income & $\begin{array}{l}\text { Individuals with a higher } \\
\text { number of pain sites } \\
\text { demonstrate lower income }\end{array}$ \\
\hline $\begin{array}{l}\text { Leveille } \\
\text { et al } \\
(2005)^{39}\end{array}$ & 1,062 & $72-99$ & $\begin{array}{l}\text { Self-reported pain on most days marked } \\
\text { on a diagram (included upper and lower } \\
\text { extremity joints, four areas on the back } \\
\text { and neck, hand joints, and joints in the } \\
\text { feet); number of painful sites categorized } \\
\text { as: no pain, pain in one region, pain in } \\
\text { two to three regions, or widespread pain } \\
\text { (ACR criteria) }\end{array}$ & $\begin{array}{l}\text { Depressive symptoms } \\
\text { defined as a score of } \\
>16 \text { on the Center for } \\
\text { Epidemiologic Studies } \\
\text { Depression Scale }\end{array}$ & $\begin{array}{l}\text { In women, individuals with a } \\
\text { higher number of pain sites } \\
\text { demonstrate higher depressive } \\
\text { symptoms; this association is } \\
\text { not significant for men }\end{array}$ \\
\hline $\begin{array}{l}\text { Leveille } \\
\text { et al } \\
(2009)^{15}\end{array}$ & 749 & $\geq 70$ & $\begin{array}{l}\text { Self-reported pain in the previous month } \\
\text { and present for at least } 3 \text { months in } \\
\text { the previous year across multiple joint } \\
\text { regions (hands/wrists, shoulders, back, } \\
\text { chest, hips, knees, and feet); number of } \\
\text { pain sites categorized as no pain, pain in } \\
\text { a single location, or pain in two or more } \\
\text { locations }\end{array}$ & $\begin{array}{l}\text { Self-reported years of } \\
\text { education }\end{array}$ & $\begin{array}{l}\text { Multisite pain is associated with } \\
\text { fewer years of education }\end{array}$ \\
\hline $\begin{array}{l}\text { Mänty et al } \\
(2014)^{19}\end{array}$ & $\begin{array}{l}\text { I, I } 77 \text { (baseline) } \\
\text { and } 709 \text { ( } 2 \text {-year } \\
\text { follow-up) }\end{array}$ & $92-93$ & $\begin{array}{l}\text { Self-reported pain with movement or } \\
\text { at rest across several sites (hips, knees, } \\
\text { and/or back); number of pain sites } \\
\text { categorized as: no pain, single site pain, } \\
\text { or multisite pain }\end{array}$ & $\begin{array}{l}\text { Depressive symptoms } \\
\text { using the Cambridge } \\
\text { Mental Disorders of the } \\
\text { Elderly Examination }\end{array}$ & $\begin{array}{l}\text { The number of baseline } \\
\text { pain sites is associated with } \\
\text { increased depressive symptoms }\end{array}$ \\
\hline $\begin{array}{l}\text { Onder et al } \\
(2005)^{41}\end{array}$ & 4,010 & $\geq 65$ & $\begin{array}{l}\text { Self-reported pain or discomfort over } \\
\text { the past } 7 \text { days; sum of reported areas } \\
\text { determined the number of painful sites }\end{array}$ & $\begin{array}{l}\text { Minimum Data Set for } \\
\text { Home Care Depression } \\
\text { Rating Scale }\end{array}$ & $\begin{array}{l}\text { In women, there is an } \\
\text { increased association between } \\
\text { pain and depression as the } \\
\text { number of painful sites } \\
\text { increases; this association is } \\
\text { not significant for men }\end{array}$ \\
\hline $\begin{array}{l}\text { Thapa et al } \\
(2018)^{14}\end{array}$ & 749 & $\geq 70$ & $\begin{array}{l}\text { Self-reported pain in the prior month } \\
\text { and present for at least } 3 \text { months in the } \\
\text { prior year across several joint areas } \\
\text { (hands/wrists, shoulders, back, chest, } \\
\text { hips, knees, feet); number of pain sites } \\
\text { categorized as: no pain, pain in a single } \\
\text { site, or multisite pain (two sites or more) }\end{array}$ & $\begin{array}{l}\text { Depression using the } \\
\text { Center for Epidemiologic } \\
\text { Studies Depression Scale; } \\
\text { Anxiety using the Hospital } \\
\text { Anxiety and Depression } \\
\text { Scale }\end{array}$ & $\begin{array}{l}\text { Compared to individuals } \\
\text { with no pain, individuals with } \\
\text { multisite pain demonstrate } \\
\text { higher depression and higher } \\
\text { anxiety }\end{array}$ \\
\hline
\end{tabular}

Abbreviation: ACR, American College of Rheumatology.

poor physical function. Further, multisite pain in older individuals is associated with psychological dysfunction (specifically, anxiety and depressive symptoms) and social factors (income and education). Detailed descriptions of the functional implications of multisite pain in older adults are outlined below. 


\section{Multisite pain and physical function in older adults}

Evidence demonstrates that multiple aspects of physical function are impacted by multisite pain in older adults (Table 1).

\section{Reduced lower extremity mobility}

Evidence indicates that multisite pain is associated with decreased lower extremity mobility. In older adults, there is a negative association between increased multisite pain and reduced lower extremity mobility test scores. ${ }^{12-14}$ Older adults with more pain sites demonstrate greater difficulty when performing specific lower extremity tasks, such as standing up, walking, and climbing stairs. ${ }^{12,15,16}$ Another study indicates that a higher number of pain sites is associated with decreased daily steps and lower moderate to vigorous physical activity as measured by lower-extremity accelerometers. ${ }^{17}$ Further, community-dwelling older adults with multisite pain also demonstrate slower gait speeds, ${ }^{12,15,18,19}$ impaired gait function, ${ }^{20}$ and reduced walking distance..$^{21}$ Multisite painrelated gait impairments are of particular concern in older populations as slower gait speed is an established risk factor for multiple, negative functional, and clinical outcomes ${ }^{22}$ (eg, risk for self-care dependence, ${ }^{23,24}$ falls, ${ }^{25,26}$ hospitalization, and institutionalization). ${ }^{25,27,28}$

\section{Upper extremity impairments}

There is evidence suggesting a potential relationship between multisite pain and reduced upper extremity performance. Older adults with a higher number of pain sites are more likely to report an inability to reach overhead and carry 10 pounds compared to those with only one pain site. ${ }^{12}$ Further, individuals with a higher number of pain sites demonstrate decreased grip strength. ${ }^{12,19}$ The limited evidence investigating the relationship between multisite pain and upper extremity function highlights the large gap in understanding the extent of multisite pain's impact across functional domains.

\section{Decreased balance and increased fall risk}

Falls are commonly experienced by approximately one-third of older adults; ${ }^{29,30}$ injuries from falls are associated with adverse outcomes, such as death, disability, and hospitalization. ${ }^{31,32}$ Older individuals are at increased risk for falls due to multiple factors, including decreased balance. ${ }^{33,34}$ Thus, an examination of multisite pain's contribution to balance deficits and heightened fall risk is warranted. Indeed, community-dwelling older adults with increased pain sites are more likely to have poor balance performance. ${ }^{15}$ Older adults with multisite pain are also more likely to report balance and coordination problems and limited activity due to balance and coordination impairments. ${ }^{35}$ Additionally, a higher number of pain sites and multisite pain are both associated with an increased history of falls. ${ }^{15,35,36}$ Further, older adults reporting an increased number of pain sites are more likely to report increased fear of falling. ${ }^{35}$

\section{Higher general disability and poor physical function}

Associations between multisite pain and general measures of perceived disability among older adults strongly indicate that multisite pain is positively related to higher levels of self-reported disability in this population. In older adults, a higher number of pain sites increases the risk for disability, ${ }^{37,38}$ decreased physical function, ${ }^{13,21}$ and impaired basic and instrumental activities of daily living (ADL). ${ }^{13,18,19}$ Persistence of multisite pain is associated with a greater likelihood of selfreported difficulty with basic and instrumental ADL, suggesting that this relationship is maintained over time. ${ }^{13}$ Further, older individuals with multisite pain are more likely to develop moderate to severe self-reported disability. ${ }^{19}$ Of note, one additional study shows that men with more pain sites demonstrate greater disability, but this relationship was not significant for women. ${ }^{39}$

\section{Multisite pain and psychosocial function in older adults}

Evidence indicates that psychosocial function is impacted by multisite pain in older adults (Table 2). An increased number of pain sites is associated with increased depressive symptoms in older adults. ${ }^{19,40}$ Of note, in two additional studies, this relationship was only seen in women and not in men, indicating a potential gender interaction. ${ }^{39,41}$ Older adults with multisite pain also report higher rates of depression and anxiety. ${ }^{14}$ Furthermore, social factors may also play a role in multisite pain among older adults. Studies suggest that multisite pain is associated with fewer years of education ${ }^{15,18}$ and lower income. ${ }^{21}$ While multisite pain appears to be associated with several psychosocial factors, there are limited studies investigating this relationship specifically in older adults. Therefore, a comprehensive investigation of both negative and positive psychological factors, as well as multiple social factors is necessary to address this clear gap in evidence.

\section{Discussion}

The current review indicates multisite pain may be associated with both decreased physical and psychosocial function in older adults. However, there continues to be limited understanding of these relationships. This review highlights 
the scant number of studies investigating functional implications of multisite pain in an aging population. This may be due to the current focus of clinical research studies on individual pain sites and/or specific conditions (eg, hand, hip, knee osteoarthritis, low back pain) among older adults. In addition, while multisite pain appears to have functional consequences, the neurobiological mechanisms contributing to this relationship are unclear. Unfortunately, investigation of multisite pain beyond musculoskeletal conditions in older adults is also limited; while some studies include investigation of general widespread pain, examination of specific neuropathic and/or widespread pain conditions as well as other comorbid diseases is currently lacking. Furthermore, what specific conditions may be more strongly associated with multisite pain symptoms and/or development of a multisite pain disease is unclear. Associations between multisite pain and other comorbidities may provide additional insight into the pathophysiological processes leading to certain functional impairments.

This review also highlights the insufficient literature on multisite pain and psychosocial function. Our search only yielded depression and anxiety assessments in relation to multisite pain. Alone, these constructs do not adequately represent overall psychological health. Thus, future studies including more comprehensive psychological batteries validated in older individuals are needed with respect to multisite pain. Finally, 2 of the 17 studies indicate a potential gender interaction in relation to multisite pain. ${ }^{39,41}$ Given that chronic pain is more common in women compared to men, it is possible that a gender interaction does play a role in the relationship between multisite pain and functional outcomes in older adults. However, future studies designed to address this question specifically are needed to draw any solid conclusions. Overall, this review strongly reiterates that the pathways by which multisite pain contributes to the variability in pain-related clinical and functional outcomes among older adults are still not fully realized.

Furthermore, this review suggests that there is an inadequate understanding of the biological mechanisms underlying multisite pain in older individuals. In aging populations, individuals with increased pain sensitization reflective of central nervous system changes also report multiple pain sites simultaneously. ${ }^{42-44}$ Similarly, other studies report that impaired conditioned pain modulation in musculoskeletal conditions is often accompanied by multisite pain (eg, chronic low back pain, knee osteoarthritis). ${ }^{45-48}$ Thus, it is possible that multisite pain is not just simply a consequence of "turning on pain pathways" in the periphery via a particular pathology but, may reflect, the state of excitability of pain circuits within the central nervous system. Multiple pain sites may translate into multiple pain inputs resulting in activitydependent shifts in the sensitivity of the pain system such that perceptual responses to noxious inputs are exaggerated, prolonged, and widespread. ${ }^{49}$ In aggregate, current studies do not imply that peripheral factors are unimportant in multisite pain; rather that peripheral factors alone are likely insufficient to account for symptoms in some, or many, older individuals with multisite pain. Whether or not central nervous system augmentation plays a prominent role in multisite pain is likely to be tied to genetic predisposition, environmental stressors, and the degree of morbidity burden a given person experiences consistent with the biopsychosocial model. Overall, investigation of the biological mechanisms associated with, and underlying, multisite pain is warranted in older persons as these changes may be important pathophysiological links explaining how multisite pain leads to subsequent negative disability and mortality.

\section{Future directions}

Studies aimed at characterizing these complex relationships using a biopsychosocial framework are necessary to fully understand multisite pain as a distinct clinical pain entity and its impact on function in older adults (Figure 1). This research approach directly aligns with recent calls to consider painrelated nervous system processes and their impact on function in chronic pain diseases. ${ }^{50,51}$ To advance the understanding of multisite pain specifically in older adults, future studies should include several key components. First, multisite pain must be appropriately defined and measured, distinguishing it from other conditions such as widespread pain conditions like fibromyalgia. Second, further investigations into potential neural peripheral and centrally-mediated mechanisms of multisite pain are of high importance. Future studies must clearly describe: 1) sensory changes including severity and frequency of multisite pain and central sensitization status; 2) pain-related negative and positive psychological processes, such as pain catastrophizing, psychological distress, pain self-efficacy, and optimism; and 3) motor-related factors, such as muscle strength, force output, muscle activation, and speed of motor unit recruitment. Third, future research is needed in older adult population to easily and effectively integrate multisite pain assessment in clinical settings. This will aid in diagnosis, treatment, and monitoring of longitudinal outcomes, including response to interventions specifically in an aging population. Finally, research needs to take into consideration the important interactions among biological, psychological, and social contributors to the multisite 
pain experience. For example, gender differences, as well as the role of age-related comorbidities (ie, pain-related, nonpain-related, and psychological) should be considered. Studies aligned with these research directions are critical to establish how multisite pain impacts function and increases the risk for disability and mortality in an aging population.

\section{Clinical implications}

Clinicians should be aware of the functional implications of multisite pain in older adults and should also recognize that multisite site pain may have its own unique underlying mechanisms with a broad impact on physical and psychosocial health. Older individuals with multisite pain may experience a disproportionately greater decline in daily physical activities and may have greater psychological and social barriers to overcome due to this pain condition and multiple, simultaneous pain inputs. Thus, utilization of multisite pain measures, psychosocial screening tools, and performance-based outcomes is essential when evaluating older adults with potential multisite pain. This type of multidimensional approach is critical for guiding selection of effective, personalized medicine strategies to enhance pain relief and optimize clinical and functional outcomes in an aging population. Finally, it is plausible that interventions aimed at controlling pain, reducing psychological distress, improving pain coping, and/or optimizing movement, all have the potential to modify the physical and psychosocial functional outcomes highlighted in this review. Indeed, biopsychosocial treatment approaches and interventions with multiple treatment targets (ie, cognitive--behavioral therapy and multidisciplinary pain programs) have shown promise across pain populations. ${ }^{52-57}$ Thus, it is conceivable that these interventions may also be appropriate for treating multisite pain in older adults, especially considering the biopsychosocial aspects of this condition.

\section{Acknowledgments}

KAB's PhD. training is supported by the National Institutes of Health T-32 Neuromuscular Plasticity Training Pre-Doctoral Fellowship (NIH T32 HD 043730), Foundation for Physical Therapy Promotion of Doctoral Studies (PODS; Level I and II) Scholarships, International Chapter of the P.E.O. Sisterhood Scholar Award, and Brooks-PHHP Research Collaboration. TWB's effort on this project was also supported in part by the NIH Rehabilitation Research Resource to Enhance Clinical Trials funded by a grant from the National Center for Medical Rehabilitation Research (P2CHD086851). YCA is supported by the National Institutes of Health/National Institute on Aging (R01AG059809, K01AG048259), and the University of Florida Claude D. Pepper Older Americans Independence Center (P30AG028740).

\section{Disclosure}

The authors report no conflicts of interest in this work.

\section{References}

1. Carnes D, Parsons S, Ashby D, et al. Chronic musculoskeletal pain rarely presents in a single body site: results from a UK population study. Rheumatology (Oxford). 2007;46(7):1168-1170.

2. Coggon D, Ntani G, Palmer KT, et al. Patterns of multisite pain and associations with risk factors. Pain. 2013;154(9):1769-1777.

3. Davies HT, Crombie IK, Macrae WA. Where does it hurt? Describing the body locations of chronic pain. Eur J Pain. 1998;2(1):69-80.

4. Macfarlane GJ, Hunt IM, Silman AJ. Role of mechanical and psychosocial factors in the onset of forearm pain: prospective population based study. BMJ. 2000;321(7262):676-679.

5. Von Korff M, Crane P, Lane M, et al. Chronic spinal pain and physicalmental comorbidity in the United States: results from the national comorbidity survey replication. Pain. 2005;113(3):331-339.

6. Hagen E M, Svensen E, Eriksen HR, Ihlebæk CM, Ursin H. Comorbid subjective health complaints in low back pain. Spine (Phila Pa 1976). 2006;31(13):1491-1495.

7. Picavet HS, Schouten JS. Musculoskeletal pain in the Netherlands: prevalences, consequences and risk groups, the DMC(3)-study. Pain 2003;102(1-2):167-178.

8. KamaleriY, Natvig B, Ihlebaek CM, Bruusgaard D. Localized or widespread musculoskeletal pain: does it matter? Pain. 2008;138(1):41-46.

9. Croft P, Dunn KM, Von Korff M. Chronic pain syndromes: you can't have one without another. Pain. 2007;131(3):237-238.

10. Garland EL. Pain processing in the human nervous system: a selective review of nociceptive and biobehavioral pathways. Prim Care Clin Off Pract. 2012;39(3):561-571.

11. Blackwell DL, Lucas JW, Clarke TC. Summary health statistics for US adults: national health interview survey, 2012. Vital Health Stat 10. 2014;(260):1-161.

12. Patel KV, Guralnik JM, Dansie EJ, Turk DC. Prevalence and impact of pain among older adults in the United States: findings from the 2011 national health and aging trends study. Pain. 2013;154(12): 2649-2657.

13. Fowler-Brown A, Wee CC, Marcantonio E, Ngo L, Leveille S. The mediating effect of chronic pain on the relationship between obesity and physical function and disability in older adults. J Am Geriatr Soc. 2013;61(12):2079-2086.

14. Thapa S, Shmerling RH, Bean JF, Cai Y, Leveille SG. Chronic multisite pain: evaluation of a new geriatric syndrome. Aging Clin Exp Res. Epub 2018 Oct 25.

15. Leveille SG, Jones RN, Kiely DK, et al. Chronic musculoskeletal pain and the occurrence of falls in an older population. JAMA. 2009;302(20):2214-2221.

16. Eggermont LH, Shmerling RH, Leveille SG. Tender point count, pain, and mobility in the older population: the mobilize Boston study. J Pain 2010;11(1):62-70.

17. Murata S, Doi T, Sawa R, Nakamura R, et al. Association between objectively measured physical activity and the number of chronic musculoskeletal pain sites in community-dwelling older adults. Pain Med. Epub 2018 Jun 6.

18. Buchman AS, Shah RC, Leurgans SE, Boyle PA, Wilson RS, Bennett DA. Musculoskeletal pain and incident disability in community-dwelling older adults. Arthritis Care Res (Hoboken). 2010;62(9):1287-1293.

19. Mänty M, Thinggaard M, Christensen K, Avlund K. Musculoskeletal pain and physical functioning in the oldest old. Eur J Pain 2014;18(4):522-529. 
20. Sawa R, Doi T, Misu S, et al. The severity and number of musculoskeletal pain associated with gait in community-dwelling elderly individuals. Gait Posture. 2017;54:242-247.

21. Leveille SG, Cohen-Mansfield J, Guralnik JM. The impact of chronic musculoskeletal pain on exercise attitudes, self-efficacy, and physical activity. J Aging Phys Act. 2003;11(2):275-283.

22. Fritz S, Lusardi M. White paper: "walking speed: the sixth vital sign". J Geriatr Phys Ther. 2009;32(2):2-5.

23. Shimada H, Suzuki T, Suzukawa M, et al. Performance-based assessments and demand for personal care in older Japanese people: a crosssectional study. BMJ Open. 2013;3(4):e002424.

24. Shinkai S, Watanabe S, Kumagai S, et al. Walking speed as a good predictor for the onset of functional dependence in a Japanese rural community population. Age Ageing. 2000;29(5):441-446.

25. Montero-Odasso M, Schapira M, Soriano ER, et al. Gait velocity as a single predictor of adverse events in healthy seniors aged 75 years and older. J Gerontol A Biol Sci Med Sci. 2005;60(10):1304-1309.

26. Chu LW, Chi I, Chiu AY. Incidence and predictors of falls in the Chinese elderly. Ann Acad Med Singapore. 2005;34(1):60-72.

27. Cesari M, Kritchevsky SB, Penninx BW, et al. Prognostic value of usual gait speed in well-functioning older people - results from the health, aging and body composition study. J Am Geriatr Soc. 2005;53(10):1675-1680.

28. Woo J, Ho SC, Yu AL. Walking speed and stride length predicts 36 months dependency, mortality, and institutionalization in Chinese aged 70 and older. J Am Geriatr Soc. 1999;47(10):1257-1260.

29. Hausdorff JM, Rios DA, Edelberg HK. Gait variability and fall risk in community-living older adults: a 1-year prospective study. Arch Phys Med Rehabil. 2001;82(8):1050-1056.

30. Hornbrook MC, Stevens VJ, Wingfield DJ, Hollis JF, Greenlick MR, Ory MG. Preventing falls among community-dwelling older persons: results from a randomized trial. Gerontologist. 1994;34(1):16-23.

31. Alexander BH, Rivara FP, Wolf ME. The cost and frequency of hospitalization for fall-related injuries in older adults. Am J Public Health. 1992;82(7):1020-1023.

32. Stevens JA. Falls among older adults - risk factors and prevention strategies. J Safety Res. 2005;36(4):409-411.

33. Vermeulen J, Neyens JC, Spreeuwenberg MD, et al. The relationship between balance measured with a modified bathroom scale and falls and disability in older adults: a 6-month follow-up study. J Med Internet Res. 2015;17(5):e131.

34. Muir SW, Berg K, Chesworth B, Klar N, Speechley M. Quantifying the magnitude of risk for balance impairment on falls in communitydwelling older adults: a systematic review and meta-analysis. J Clin Epidemiol. 2010;63(4):389-406.

35. Patel KV, Phelan EA, Leveille SG, et al. High prevalence of falls, fear of falling, and impaired balance in older adults with pain in the United States: findings from the 2011 National Health and aging trends study. J Am Geriatr Soc. 2014;62(10):1844-1852.

36. Asai T, Misu S, Sawa R, Doi T, Yamada M. Multi-chronic musculoskeletal pain is a useful clinical index to predict the risk of falls in older adults with normal motor function. Aging Clin Exp Res. 2015;27(5):711-716.

37. Landi F, Russo A, Liperoti R, et al. Daily pain and functional decline among old-old adults living in the community: results from the ilSIRENTE study. J Pain Symptom Manage. 2009;38(3):350-357.

38. Scudds RJ, Robertson JM. Pain factors associated with physical disability in a sample of community-dwelling senior citizens. J Gerontol A Biol Sci Med Sci. 2000;55(7):M393-M399.
39. Leveille SG, Zhang Y, McMullen W, Kelly-Hayes M, Felson DT. Sex differences in musculoskeletal pain in older adults. Pain. 2005;116(3):332-338.

40. Denkinger MD, Lukas A, Nikolaus T, Peter R, Franke S; ActiFE Study Group. Multisite pain, pain frequency and pain severity are associated with depression in older adults: results from the ActiFE Ulm study. Age Ageing. 2014;43(4):510-514.

41. Onder G, Landi F, Gambassi G, et al. Association between pain and depression among older adults in Europe: results from the aged in home care (AdHOC) project: a cross-sectional study. J Clin Psychiatry. 2005;66(8):982-988.

42. Cruz-Almeida Y, Cardoso J, Riley JL, et al. Physical performance and movement-evoked pain profiles in community-dwelling individuals at risk for knee osteoarthritis. Exp Gerontol. 2017;98:186-191.

43. Cardoso JS, Riley JL, Glover T, et al. Experimental pain phenotyping in community-dwelling individuals with knee osteoarthritis. Pain. 2016;157(9):2104-2114.

44. Cruz-Almeida Y, King CD, Goodin BR, et al. Psychological profiles and pain characteristics of older adults with knee osteoarthritis. Arthritis Care Res. 2013;65(11):1786-1794.

45. Naugle KM, Cruz-Almeida Y, Fillingim RB, Riley JL 3rd. Offset analgesia is reduced in older adults. Pain. 2013;154(11):2381-2387.

46. Naugle KM, Cruz-Almeida Y, Fillingim RB, Staud R, Riley JL 3rd. Increased spatial dimensions of repetitive heat and cold stimuli in older women. Pain. 2017;158(5):973-979.

47. Simon CB, Riley JL III, Coronado RA, et al. Older age as a prognostic factor of attenuated pain recovery after shoulder arthroscopy. $P M R$. 2016;8(4):297-304.

48. Riley JL, King CD, Wong F, Mauderli AP. Lack of endogenous modulation and reduced decay of prolonged heat pain in older adults. Pain. 2010;150(1):153-160.

49. Woolf CJ. Central sensitization: implications for the diagnosis and treatment of pain. Pain. 2011;152(3 Suppl):S2-S15.

50. Institute of Medicine. Relieving Pain in America: A Blueprint for Transforming Prevention $C$, Education, and Research. Washington (DC): National Academies Press (US); 2011.

51. Butera KA, Fox EJ, George SZ. Toward a transformed understanding: from pain and movement to pain with movement. Phys Ther. 2016;96(10):1503-1507.

52. Lamb SE, Hansen Z, Lall R, et al; Back Skills Training Trial investigators. Group cognitive behavioural treatment for low-back pain in primary care: a randomised controlled trial and cost-effectiveness analysis. Lancet. 2010;375(9718):916-923.

53. Archer KR, Devin CJ, Vanston SW, et al. Cognitive-behavioral-based physical therapy for patients with chronic pain undergoing lumbar spine surgery: a randomized controlled trial. J Pain. 2016;17(1):76-89.

54. Flor H, Fydrich T, Turk DC. Efficacy of multidisciplinary pain treatment centers: a meta-analytic review. Surv Anesthesiol. 1993;37(1):29.

55. Lang E, Liebig K, Kastner S, Neundörfer B, Heuschmann P. Multidisciplinary rehabilitation versus usual care for chronic low back pain in the community: effects on quality of life. Spine J. 2003;3(4): 270-276.

56. Patrick LE, Altmaier EM, Found EM, Patrick LE. Long-term outcomes in multidisciplinary treatment of chronic low back pain: results of a 13-year follow-up. Spine (Phila Pa 1976). 2004;29(8):850-855.

57. Main CJ, George SZ. Psychologically informed practice for management of low back pain: future directions in practice and research. Phys Ther. 2011;91(5):820-824. 
The Journal of Pain Research is an international, peer reviewed, open access, online journal that welcomes laboratory and clinical findings in the fields of pain research and the prevention and management of pain. Original research, reviews, symposium reports, hypothesis formation and commentaries are all considered for publication
The manuscript management system is completely online and includes a very quick and fair peer-review system, which is all easy to use. Visit http://www.dovepress.com/testimonials.php to read real quotes from published authors.

Submit your manuscript here: https://www.dovepress.com/journal-of-pain-research-journal 